\title{
The Smart Growth Measurement and Comparison Model Based on the Principal Component Analysis
}

\author{
Wuyu Zhang ${ }^{1, a}$ \\ ${ }^{1}$ School of Electrical \& Electronic Engineering, North China Electric Power University, Baoding \\ 071000, China \\ azwy5432@163.com
}

Keywords: smart growth, principal component analysis, metric.

\begin{abstract}
Smart growth is about helping cities become economically prosperous, socially equitable, and environmentally sustainable place to live. The purpose of this paper is establishing a model to measure and compare the smart growth degree. Principle component analysis is a suitable method since the factors affecting the smart growth degree are complicated. These factors involve ten principles of smart growth and three E's of sustainability. Through selecting the principle components, I can simplify the method of evaluation at most. Then I choose Cleveland in US and Jiayuguan in China as research objects. According the model, I got the scores on each indicators about each cities, also got the final smart growth of each cities.
\end{abstract}

\section{Introduction}

Development is an eternal purpose pursued by the governments. From the length of our daily commute to the price of a new home to the safety of our neighborhoods--issues I care about are all influenced by development decisions.

Smart growth is about helping cities become economically prosperous, socially equitable, and environmentally sustainable place to live. Meanwhile, the core of smart growth is the ten principles involving land uses, community development, transportation choices and decision makings, including almost every aspect of daily life. The edges of the sustainable development are obvious. In other words, it is a powerful tool for a city to accelerate the speed of urbanization and accomplish the expected blueprints. Moreover, the priority of the ten principles and three E's vary taking account of the current situation of a city. Thus the following development plans need to be adjusted to match the criterion more perfectly. It is complex and imprecise if the decision makers merely refer to the textual principles without using a quantitative tool to measure.

\section{The principal component analysis model}

Symbol Definitions.

Table 1 Symbols of model

\begin{tabular}{|c|c|}
\hline $\begin{array}{l}\text { symbols } \\
S_{j}\end{array}$ & $\begin{array}{l}\text { definitions } \\
\text { the smart growth principle's standardized score }\end{array}$ \\
\hline$n_{j}$ & number of indicators within the principle( scale $0-10$ ) \\
\hline$D_{i}$ & the indicator's scores ( scale 0 -2) \\
\hline$S_{\text {total }}$ & smart growth index of a city's development plan \\
\hline SGPi & the indicator of smart growth principle \\
\hline
\end{tabular}

Outline of the Approach.

With all aspects taken into account, I select 16 indicators to indicate the 10 principles of smart growth and the three E's of sustainability, revealed in Table 2. To measure the success of smart growth of a city quantitatively, I establish smart growth index as the core of our model. The building of the index includes five steps. 
The first step is to assign scores, which range from 0 (unsuccessful) to 1 (relatively successful) and 2 (very successful). The policy needs to be judged referring to all the indicators and will get a score. If the indicator is not revealed in the policy, then the policy will get a score of 0 with regard to this indicator. Moreover, a score of 1 will be assigned to a policy if the indicator does appear and is described using suggestive words like: may, should, prefer, encourage and suggest. Similarly, a policy will get a score of 2 when the indicator exists and is stated with mandatory words like shall, mandated, must and will. The second step is to add up the scores of a policy with regard to all the indicators belonging to one principle. The third step is calculating the fractional scores of each principle through dividing the score achieved in the former step by the maximum scores of each principle. Maximum scores imply that all of the indicators are mandatory. For example, the maximum score of a principle including 4 indicators is 8 . In the fourth step, the fractional scores are standardized by multiplying the fractional score by 10 , so that scores for each principle can be scaled on a range between 0 and 10 .

$$
S_{j}=\frac{10}{2 n_{j}} \sum_{i=1}^{n_{j}} D_{i}
$$

Finally, the smart-growth index of a city is achieved by adding up the standardized score of all of the smart-growth principles.

$$
S_{\text {total }}=S_{1}+S_{2}+S_{3}+\cdots+S_{j}
$$

Since number of the principles is 13, the smart growth index ranges from 0 to 130 .

\begin{tabular}{|c|c|c|}
\hline $\begin{array}{c}\text { Number of variable } \\
1\end{array}$ & $\begin{array}{l}\text { Indicators } \\
\text { GDP }\end{array}$ & $\begin{array}{c}\text { Three E's and } 10 \text { principles of smart growth } \\
\text { Economically prosperous }\end{array}$ \\
\hline 2 & GDP growth rate & \\
\hline 3 & Per capita income & Socially equitable \\
\hline 4 & Gini coefficient & \\
\hline 5 & Per capita area & Environmentally sustainable \\
\hline 6 & Open space ratio & \\
\hline 7 & SGP1 & Mix land uses \\
\hline 8 & SGP2 & Take advantage of compact building design \\
\hline 9 & SGP3 & Create a range of housing opportunities and choices \\
\hline 10 & SGP4 & Create walkable neighborhoods \\
\hline 11 & SGP5 & $\begin{array}{l}\text { Foster distinctive, attractive communities with a strong } \\
\text { sense of place }\end{array}$ \\
\hline 12 & SGP6 & $\begin{array}{l}\text { Preserve open space, farmland, nature beauty, and } \\
\text { critical environmental areas }\end{array}$ \\
\hline 13 & SGP7 & $\begin{array}{l}\text { Strengthen and direct development towards existing } \\
\text { communities }\end{array}$ \\
\hline 14 & SGP8 & Provide a variety of transportation choices \\
\hline 15 & SGP9 & $\begin{array}{c}\text { Make development decisions predictable, fair, and cost } \\
\text { effective }\end{array}$ \\
\hline 16 & SGP10 & $\begin{array}{c}\text { Encourage community and stakeholder collaboration in } \\
\text { development decisions }\end{array}$ \\
\hline
\end{tabular}

Table 2 Evaluation protocol for Smart Growth in the Local Development Plans 


\section{Evaluation of the model.}

To increase the reliability of the model, the evaluation should be conducted. The plans are evaluated by several coders working together independently of each other at the same time. An inter-coder reliability score referred to as a percentage agreement is computed. It is obtained by dividing the total number of disagreements received in coding by the total number of both disagreement and agreement and multiplying 100. A score higher than $80 \%$ is universally regarded as acceptable. After evaluation, the score of this model is $85 \%$, which suggests that the model is feasible.

\section{Evaluation in current plans of the two cities}

\section{Data preprocessing.}

I select two cities: Cleveland and Jiayuguan, which are located in America and Asia and have population of about 388072 and 300000 respectively. I searched the data and polices of the two selected cities with respect to each indicator. According to the model I have just established, I got the scores on each indicators about each cities, which are revealed in the Table 3 and Table 4.

Table 3 Scores on each indicators of Cleveland

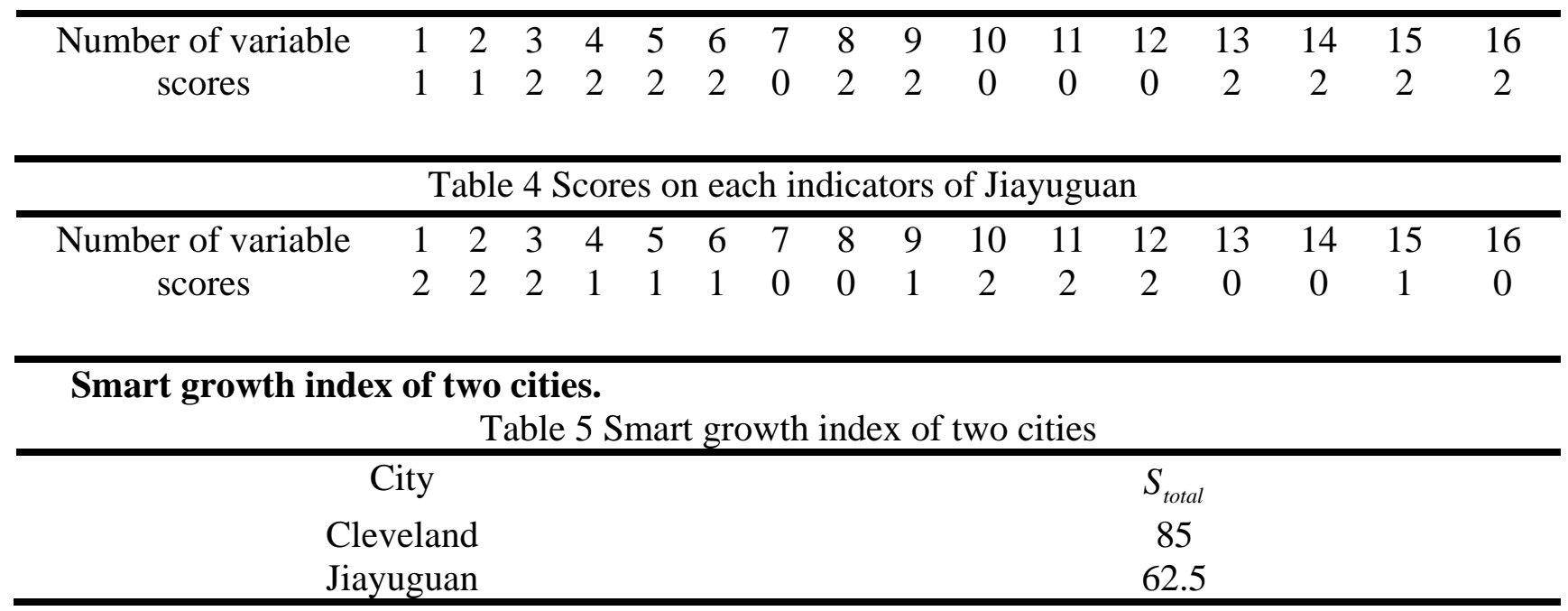

\section{Conclusions}

As revealed in the Table 5, the final smart growth index of Cleveland is 85, accounting for $65.38 \%$ of the scale. It suggests that the current growth plan of Cleveland meets the $3 \mathrm{E}$ 's and 10 principles of smart growth relatively well in general. In other words, the current plans of Cleveland are reasonable to some degree. However, some principles, namely the mix land uses, create walkable neighborhoods, foster distinctive, attractive communities with a strong sense of place and the preserve open space, farmland, nature beauty, and critical environmental areas are not mentioned, which makes the growth plan defective.

As revealed in the Table 3.3, the final smart growth index of Jiayuguan is 62.5, accounting for $48.08 \%$ of the scale. It suggests that the current growth plan of Jiayuguan does not meet the 3 E's and 10 principles of smart growth relatively well in general. In other words, the current plans of Jiayuguan are not successful to some degree. Some principles, namely the mix land uses, take advantage of compact building design, strengthen and direct development towards existing communities, provide a variety of transportation choices, encourage community and stakeholder collaboration in development decisions are not mentioned in the plan.

\section{Acknowledgments}

My deepest gratitude goes first and foremost to Teacher Gu, our supervisor, for her constant encouragement and guidance. She has walked me through all the stages of the writing of this thesis. Without her consistent and illuminating instruction, this thesis could not have reached its present 
form. Second, I would like to express my heartfelt gratitude to Songqiao Tang, my roommate, who led me into the world of data. I also owe my sincere gratitude to my friends and my fellow classmates who gave me their help and time in listening to me and helping me work out my problems during the difficult course of the thesis.

\section{References}

[1] Raparthi, Kiranmayi. Assessing Smart-Growth Strategies in Indian Cities: Grounded Theory Approach to Planning Practice. Journal of Urban Planning \&Development 141.4(2014):05014031.

[2] Philip R. Berke, and Maria Manta Conroy. Are We Planning for Sustainable Development?" Journal of the American Planning Association 66.1(2000):21-33.

[3] City of Cleveland, 2006-2014 states of the city, Retrieved from http://www.city.cleveland.oh.us.

[4] U.S. Department of Commerce, Population Change in Central and Outlying Counties of Metropolitan Statistical Areas: 2000 to 2007, Retrieved from https://www.bea.gov.

[5] EPA, This is Smart Growth. 2016, Retrieved from https://www.epa.gov/smartgrowth/smart-growth- publication 